\title{
The Historical Gage of Alexander: An Anthropological Dynamics Among the Highland Nomads, India
}

\author{
Banita Behera \\ Anthropological Survey of India, India
}

\begin{abstract}
A continuous effort of disseminating the knowledge of profound cultural heritage is running since decades to strengthen Museum Anthropology and to share resources of ethnographic studies for a better research. The noble idea to develop a new anthropological paradigm that began with the plantation of a few experimental ethnographic research in Museums will help to find the socio-historical roots. Besides the diachronic and synchronic enquiries by Anthropologists the documentation of inter-ethnic interaction in the context of History and Anthropology for the quest of some innovations are undergoing to help the human science to explain their historical movement and impact of other countries largely. Museums across the world underwent transformations to become more relevant, reflexive and engaged beyond the repositories and exhibitions. Talking about ethnographic studies by Museum Anthropologists in search for relevance of indigenous aboriginal, plays a major role to talk about inter global connections and to situate the cultural roots among them to maintain the authenticity of Indigenous Peoples. This paper tries to ponder upon the democratic values of high altitude community in order to express their effective link with past, Alexander the Great/ Germans and now narrating their larger existential reality in Indian Civilization. The impact of Alexander's invasion on the intellectual and social life of many communities of India is still alive, and struggling for their identity, trying to safeguard their cultural heritage. This study was aimed to explore the historical link of the nomads through anthropological study and to highlight the empirical findings done during the ethnographic study.
\end{abstract}

Keywords: Culture, Ethnography, High altitude, Historical Analysis, Museum Anthropology. 